\title{
System Suitability
}

National Cancer Institute

\section{Source}

National Cancer Institute. System Suitability. NCI Thesaurus. Code C134246.

The tests are based on the concept that the equipment, electronics, analytical

operations, and samples to be analyzed constitute an integral system that can be

evaluated as such. System suitability test parameters to be established for a particular procedure depend on the type of procedure being validated. 